\title{
Anticorrosion Efficiency of Inhibitor Coatings Based on Ammonium Cation with Different Substituents: The Influence of Wettability and Molecular Structure
}

\author{
Hanna Pianka 1,2, Sana Falah 1,3, Sandrine Zanna ${ }^{1}$, Vladimir Bezborodov ${ }^{4}{ }^{\oplus}$, Sergei Mikhalyonok ${ }^{4}$, \\ Nina Kuz'menok ${ }^{4}$, Alexander Chernik ${ }^{2}$, Yanpeng Xue ${ }^{5}$ and Abdelhafed Taleb ${ }^{1,6, *(1)}$ \\ 1 Institut de Recherche de Chimie Paris, Chimie ParisTech-CNRS, PSL University, 75005 Paris, France; \\ hanna.pianka@mail.ru (H.P.); falah.sana@chimieparistech.psl.eu (S.F.); \\ sandrine.zanna@chimieparistech.psl.eu (S.Z.) \\ 2 Department of Chemistry, Technology of Electrochemical Production and Electronic Engineering Materials, \\ Department of Organic Chemistry, Belarusian State Technological University, 13a Sverdlova Str., \\ 220006 Minsk, Belarus; alexachernik@gmail.com \\ 3 Faculté des Sciences de Tunis Campus El Manar II, El Manar University, Tunis 2029, Tunisia \\ 4 Department of Organic Chemistry, Belarusian State Technological University, 13a Sverdlova Str., \\ 220006 Minsk, Belarus; v_bezborodov@yahoo.com (V.B.); serge_msg@belstu.by (S.M.); \\ kuznm@belstu.by (N.K.) \\ 5 National Center for Materials Service Safety, University of Science and Technology Beijing, Xueyuan Road 30, \\ Beijing 100083, China; xueyanpeng789@163.com \\ 6 Sorbonne Université, 4 Place Jussieu, 75231 Paris, France

Citation: Pianka, H.; Falah, S.; Zanna S.; Bezborodov, V.; Mikhalyonok, S.; Kuz'menok, N.; Chernik, A.; Xue, Y.; Taleb, A. Anticorrosion Efficiency of Inhibitor Coatings Based on Ammonium Cation with Different Substituents: The Influence of Wettability and Molecular Structure. Coatings 2021, 11, 1512. https:// doi.org/10.3390/coatings11121512

Academic Editor: Danut-Ionel Vaireanu

Received: 31 October 2021

Accepted: 2 December 2021

Published: 9 December 2021

Publisher's Note: MDPI stays neutral with regard to jurisdictional claims in published maps and institutional affiliations.

\begin{abstract}
In this work, different cationic surfactants with various aliphatic and aromatic ammonium cations were used to prepare inhibitor coatings and were characterized by different techniques such as IR spectroscopy and NMR. The inhibitor coatings were prepared by electrografting on the steel surface and their anticorrosion properties were evaluated in different media $\left(\mathrm{HCl}, \mathrm{H}_{2} \mathrm{SO}_{4}\right.$ and $\mathrm{NaCl}$ solutions). The electrochemical potentiodynamic polarization technique was used to study the inhibition efficiency of the prepared coatings. The dependence of the wetting properties of the electrografted layer and its homogeneity on the molecular structure of the prepared surfactants was studied. Particular attention was paid to the relationship between the properties of these surfactants in terms of critical micellar concentration, packing and wetting, and the anti-corrosion efficiency of their coatings. In this paper, we discuss the synergistic inhibition effect and the anticorrosion efficiency.
\end{abstract}

Keywords: aromatic ammonium cations; inhibitor coatings; corrosion; wettability

\section{Introduction}

Materials in their working conditions are usually subjected to different degradations, which induce loss of mass, alters their properties, and limits their sustainability and usefulness. For metallic materials such as steel in aggressive media, additional degradation due to its electrochemical corrosion takes place, cations appear in the water and the corresponding negative charge is formed in the metal [1,2]. In the case of carbon steels, the first stage of the corrosion reaction takes place in the anodic region, where the iron is oxidized to ferrous ions, which pass into solution according to Reaction (1).

$$
\mathrm{Fe}(\mathrm{s})^{-}>\mathrm{Fe}^{2+}(\mathrm{aq})+2 \mathrm{e}^{-}
$$

The corrosion reaction is conditioned by the maintenance of overall electrical neutrality. Electrons are released by the oxidation of iron in the anodic region and move through the metal structure to the cathodic region adjacent to the surface, where they react with oxygen and water to form hydroxyl ions according to the Reactions (2) and (3). Therefore, the 
movement of electrons in the metal and cations in the electrolyte to the anode surfaces must be counterbalanced by one or more reduction reactions (electron consumption), depending on the electrolyte $\mathrm{pH}$, on the cathode surface side. The most common reduction reactions are the following:

$$
\begin{gathered}
\mathrm{O}_{2}(\mathrm{~g})+2 \mathrm{H}_{2} \mathrm{O}(\mathrm{l})+4 \mathrm{e}^{-} \rightarrow 4 \mathrm{OH}^{-}(\mathrm{aq}) \\
2 \mathrm{H}_{2} \mathrm{O}+2 \mathrm{e}^{-} \rightarrow \mathrm{H}_{2}(\mathrm{~g}) \uparrow+2 \mathrm{OH}^{-} \\
2 \mathrm{H}^{+}+2 \mathrm{e}^{-} \rightarrow \mathrm{H}_{2}(\mathrm{~g}) \uparrow
\end{gathered}
$$

The hydroxide ions product of Reactions (2) and (3) can react with the iron (II) ions to produce a precipitate of iron (II) hydroxide according to Reaction (5).

$$
\mathrm{Fe}^{2+}(\mathrm{aq})+2 \mathrm{OH}^{-}(\mathrm{aq}) \rightarrow \mathrm{Fe}(\mathrm{OH})_{2}(\mathrm{~s})
$$

In the presence of dissolved oxygen, this is quickly oxidized further to ferric oxyhydroxide and hematite according to Reactions (6) and (7), respectively:

$$
\begin{gathered}
2 \mathrm{Fe}(\mathrm{OH})_{2}+\mathrm{O} \rightarrow 2 \mathrm{FeOOH}+\mathrm{H}_{2} \mathrm{O} \\
4 \mathrm{Fe}(\mathrm{OH})_{2}(\mathrm{~s})+\mathrm{O}_{2}(\mathrm{~g}) \rightarrow 2 \mathrm{Fe}_{2} \mathrm{O}_{3} \cdot \mathrm{H}_{2} \mathrm{O}(\mathrm{s})+2 \mathrm{H}_{2} \mathrm{O}(\mathrm{l})
\end{gathered}
$$

To limit the deleterious corrosion effect on metallic material properties, different protective approaches were developed, such as cathodic or anodic polarization, passive or active coating [3], etc. Among these approaches, the use of inhibitor layers as passive coatings is the most popular. The efficiency of such coating depends on different parameters such as the inhibitor chemical composition [4], concentration [5], its interaction with the metal surface [6], temperature [7] and $\mathrm{pH}$ [8]. Furthermore, various quantum chemical calculations were used to illustrate the dependence of the corrosion inhibition efficiency of the coatings on the molecular structures of the inhibitors forming them $[9,10]$.

The major limitations of inhibitor layers' efficiency on the surface of metallic materials as anticorrosion passive coatings are related to adhesion and compactness. The adhesion of the inhibitor layers could be discussed in terms of adsorption of the surfactant and its compactness through its molecular structure. The inhibitors' adsorption could be physisorption-driven by the weak electrostatic interactions due to the van der Waals forces or could be chemisorption driven by a strong chemical bonding. This will depend on the specific interaction between different functional groups of used compounds and the surface of metal materials to protect. The most used organic inhibitors contain oxygen, sulfur and nitrogen atoms or aromatic heterocycle and/or double or treble bonds [11,12]. Among these organic compounds, cationic salts and those with ammonium group have proven their efficiency as an anticorrosion passive coating for steel and iron in an acidic medium [13]. Furthermore, it was also shown that aliphatic and aromatic substituents play a role in their anticorrosion efficiency [14-18]. Heterocyclic compounds bearing nitrogen atoms were reported to provide better anticorrosion efficiency than ammonium cation with only aliphatic substituents [16]. The anticorrosion efficiency was also shown to be improved with the increase in the alkyl chain length of the aliphatic substituents [19]. Since the surfactant is formed by a hydrophilic group and a hydrophobic chain, the adsorption on the surface is carried out by the hydrophilic group, and the hydrophobic chain remains oriented towards the water to minimize the interactions between the surfactant-based coating and the aqueous solvent.

Different inhibition efficiencies ranging from $50 \%$ to $99.5 \%$ were reported in the literature for quaternary ammonium surfactants [20-24]. This inhibition performance depends on the surfactant structure and properties, aggressive media and operating conditions. For example, Hergaz et al. reported an efficiency of about 99.5\% of N-(3-(2(phenyldiethylammonio)acetoxy)propyl)-N,N-dimetyldodecan-1-aminium chloride bromide at concentration of $5 \times 10^{-3} \mathrm{M}$ as an inhibitor for API $\times 65$ steel pipeline in $1 \mathrm{M}$ $\mathrm{HCl}$ [20]. They explain this performance by the inhibitor properties in terms of the presence 
of aromatic and alkyl chain substituents. They claim that the free aromatic groups with planar orientation on the substrate increase the surfactant coordination bonds with the steel substrate, and the alkyl chain enhances its packing and hydrophobic character.

Additionally, the inhibitor adsorption strength also depends on the chemical composition of the metal surface and the conditions in which the protection takes place, such as the temperature, the applied potential and the aggressive environment, as reported by different authors [25-29]. Furthermore, among the methods used for metal surface functionalization, electrografting is well known in the literature to enable the formation of bonding with covalent nature [30]. Little work has been published on the electrografting of quaternary ammonium surfactants for anti-corrosion applications.

The adsorption of the inhibitors on the metal surface forms a more or less compact layer, depending on the molecular structure of the inhibitor, which can change the wetting properties of the inhibitor-based coating. For hydrophobic or superhydrophobic coating on the metal surfaces, the diffusion of the aggressive ions through the layer is strongly reduced, which can enhance the anticorrosion efficiency of inhibitors' coating by limiting the interaction of metal surface with the aggressive ions [31]. It is well established in the literature that the anticorrosion efficiency increases with the contact angle characterizing the wetting properties of metal-coated surface [32,33]. In addition, the anticorrosion efficiency depends on the critical micelle concentrations (CMC) of inhibitors [34,35]. Around the $\mathrm{CMC}$, maximum surface coverage by the inhibitor molecules can be achieved and the anti-corrosion effectiveness should increase.

In the present work, cationic surfactants with different aliphatic, aromatic and heterocyclic substituents such as benzyldimethylphenylammonium chloride (1), $\mathrm{N}_{1}, \mathrm{~N}_{2}$-dibenzyl$\mathrm{N}_{1}, \mathrm{~N}_{1}, \mathrm{~N}_{2}, \mathrm{~N}_{2}$-tetramethylethane-1,2-diammonium dichloride (2), benzyldodecyldiethylammonium chloride (3), cetylpyridinium bromide (4) and dodecylpyridinium bromide (5) were used to prepare a coating on the steel surface, the anti-corrosion effectiveness of which was evaluated using the electrochemical Tafel polarization technique. The influence of surfactant properties in terms of molecular structure, critical micelle concentration and wetting properties on the anti-corrosion effectiveness of the prepared coating was explored and discussed for better understanding of the protection mechanism.

\section{Materials and Methods}

For the synthesis of cetylpyridinium bromide (surfactant 4), a mixture of $0.05 \mathrm{~mol}$ of pyridine and $0.05 \mathrm{~mol}$ of dodecylbromide in $10 \mathrm{~mL}$ of acetone was refluxed for $1 \mathrm{~h}$. The reaction mixture was cooled, and the obtained product was filtered and dried in a vacuum desiccator (m.p. $47-50{ }^{\circ} \mathrm{C}$, yield $98.0 \%$ ). Elementary analysis of the synthesized compound was found in \% as follows: $\mathrm{C}, 62.15 ; \mathrm{H}, 9.16 ; \mathrm{Br}, 24.31 ; \mathrm{N}, 4.22$. Calculated amounts in \% were as follows: $\mathrm{C}, 62.19 ; \mathrm{H}, 9.21 ; \mathrm{Br}, 24.34 ; \mathrm{N}, 4.27$.

Ammonium salts (surfactants 1-5) were synthesized using a similar reaction. The corresponding molecular formula and nominations are depicted in Table 1.

The used steel has the following chemical composition (wt \%): $0.22 \mathrm{C}, 0.65 \mathrm{Mn}, 0.17 \mathrm{Si}$, $0.04 \mathrm{P}, 0.05 \mathrm{~S}, 0.08 \mathrm{As}, 0.3 \mathrm{Ni}, \mathrm{Cu}, \mathrm{Cr}$ and balanced Fe. The electrodes were prepared according to the following steps. At the first stage, the steel electrodes were abraded with a series of emery papers (grade 400-2400), washed with acetone and distilled water, and then dried in the air. The surface of the steel electrodes was cleaned under sonication for $10 \mathrm{~min}$ in ethanol first, and then in ultrapure water. The steel electrode was sealed with epoxy resin, and the exposed cross-sectional area was $0.2 \mathrm{~cm}^{2}$. After drying the electrode surface under argon stream, it was modified in a second stage by electrografting.

Prepared cationic surfactants were used to functionalize the steel electrodes' surface using the electro-reduction method. In the case of cetylpyridinium bromide molecules, the electrolyte was prepared in $20 \mathrm{ml}$ solution of acetonitrile, in which $0.04 \mathrm{~g}$ cetylpyridinium bromide and $0.6 \mathrm{~g}$ of tetrabutylammonium tetrafluoroborate acid were dissolved under stirring at ambient temperature for $20 \mathrm{~min}$. Furthermore, the electrografting process was performed using the voltammetry cyclic technique in the potential range between $-1 \mathrm{~V}$ 
and $+0 \mathrm{~V}$ vs. SCE during different voltammetry cycles 12 and 24 . The same procedure was performed for other prepared cationic surfactants. The surfactant solutions used for electrografting were not degassed.

Table 1. Chemical nomenclature and chemical formulas of indicated prepared surfactants.

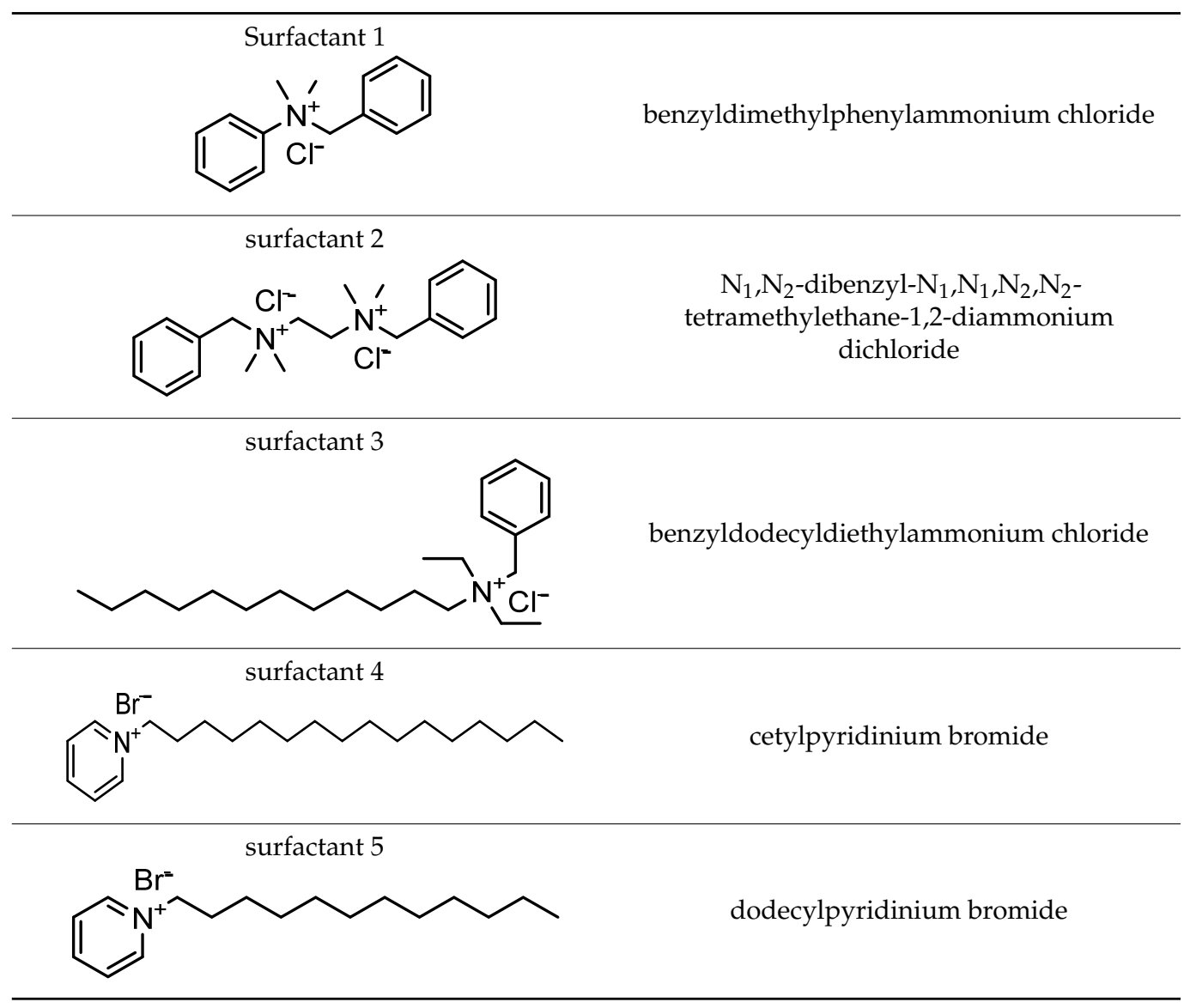

The electrochemical measurements (Tafel polarization curves) were performed with a Metrohm Autolab PGSTAT 12 Potentiostat and achieved at room temperature without any further stirring. A conventional three-electrode setup was used, in which prepared steel was used as a working electrode, platinum sheet as a counter electrode and $\mathrm{Ag} / \mathrm{AgCl}$ as a reference electrode. Before starting the measurements, the electrodes were immersed in the electrolyte solution at open circuit potential (OCP) for $20 \mathrm{~min}$, which is the time necessary to reach a steady state. The potentiodynamic polarization curves were recorded in the potential range of -1.3 to $+0.3 \mathrm{~V} \mathrm{vs}$. $\mathrm{Ag} / \mathrm{AgCl}$ (from cathodic potential to anodic potential) with a scan rate of $5 \mathrm{mV} / \mathrm{s}$. The grafting was achieved during different voltammetry cycles, 12 and 24. The electrolytes used for electrochemical measurements were not degassed.

The roughness of the prepared thin films was determined by stylus profilometry using a Dektak8 Bruker stylus profiler with a tip radius of $12.5 \mu \mathrm{m}$. The surface is characterized by its measured geometrical roughness, $\mathrm{Rq}$, defined as the root mean square average of the profile height deviation from the mean line recorded within the evaluation line.

The morphology of the bare steel electrode surface and modified with inhibitors is characterized using a high-resolution Ultra 55 Zeiss FEG scanning electron microscope (FEGSEM) operating at an acceleration voltage of $10 \mathrm{kV}$.

The chemical composition of prepared cationic surfactants is determined by X-ray photoelectron spectroscopy (XPS) and the measurements are performed on a Thermo Electron ESCALAB 250 spectrometer operating at about $10^{-9}$ bar and fitted with a microfocused, monochromatic $\mathrm{Al} \mathrm{K} \alpha \mathrm{X}$-ray source $(\mathrm{hv}=1486.6 \mathrm{eV})$. Survey spectra were recorded with the pass energy of $100 \mathrm{eV}$ at a step size of $1 \mathrm{eV}$. High-resolution spectra of the Fe 2p, 
$\mathrm{Cr} 2 \mathrm{p}, \mathrm{Ni} 2 \mathrm{p}, \mathrm{Mo} 3 \mathrm{~d}, \mathrm{O} 1 \mathrm{~s}, \mathrm{~S} 2 \mathrm{p}, \mathrm{Cl} 2 \mathrm{p}$ and $\mathrm{C} 1 \mathrm{~s}$ core level regions were recorded with a pass energy of $20 \mathrm{eV}$ at a step size of $0.1 \mathrm{eV}$. The take-off angle of the analyzed photoelectrons was $90^{\circ}$. The binding energies (BE) were calibrated by setting the $\mathrm{C} 1 \mathrm{~s}$ signal corresponding to olefinic bonds at $285.0 \mathrm{eV}$.

The infrared transmittance measurements were carried out using a Nicolet In 10 apparatus within the spectral range between 500 and $3500 \mathrm{~cm}^{-1}$.

The wetting properties of the prepared steel electrodes surface in terms of static contact angle were determined by using a Krüss DSA10 contact angle measuring apparatus, equipped with a CCD camera. A $3 \mathrm{ml}$ droplet of water purified by a milli-Q System (Millipore, electric resistivity $18.2 \mathrm{M} \Omega . \mathrm{cm}$ ) was used for these measurements.

\section{Results}

The structure of synthesized compounds was characterized by Nuclear Magnetic Resonance (NMR) and IR spectroscopes. The chemical shifts of the signals relevant to the ${ }^{1} \mathrm{H}$ and ${ }^{13} \mathrm{C}$ NMR spectra are the following for pyridinium bromide (surfactant 5 ): ${ }^{1} \mathrm{H}$ NMR (400 MHz, DMSO-d6) $0.84\left(3 \mathrm{H}, \mathrm{t}, \mathrm{J}=6.7 \mathrm{~Hz}, \mathrm{CH}_{3}\right) ; 1.16-1.30(26 \mathrm{H}, \mathrm{m}) ; 1.85-1.95(2 \mathrm{H}$, $\mathrm{m}) ; 4.62\left(2 \mathrm{H}, \mathrm{t}, \mathrm{J}=7.6 \mathrm{~Hz}, \mathrm{~N}-\mathrm{CH}_{2}\right) ; 8.17\left(2 \mathrm{H}, \mathrm{dd}, \mathrm{J}=6.6,7.6, \mathrm{Py}-\mathrm{H}_{\beta}\right) ; 8.62(1 \mathrm{H}, \mathrm{tt}, \mathrm{J}=1.2$, 7.6 Hz, Py- $\left.\mathrm{H}_{\gamma}\right)$; $9.15\left(2 \mathrm{H}, \mathrm{dd}, \mathrm{J}=1.2,6.6 \mathrm{~Hz}, \mathrm{Py}-\mathrm{H}_{\alpha}\right) .{ }^{13} \mathrm{C}$ NMR (101 MHz, DMSO-d6) 13.94; 22.10; 25.40; 28.41; 28.72; 28.81; 28.94; 29.02; 29.06 (br); 30.69; 30.75; 31.30; 60.70; 128.09; $144.76 ; 145.49$.

The IR spectroscopy characterization of the synthesized surfactants is shown in Figure 1. The bands located in the region from 1120 to $1018 \mathrm{~cm}^{-1}$ and from 850 to $750 \mathrm{~cm}^{-1}$ were assigned to asymmetrical and symmetrical stretching modes of C-N-C [27], whereas the bands at 2920 and $2851 \mathrm{~cm}^{-1}$ were attributed to the asymmetrical and symmetrical stretching mode of Csp3-H, respectively. Furthermore, the bands located at $711 \mathrm{~cm}^{-1}$ were attributed to $\left(\mathrm{CH}_{2}\right)_{\mathrm{n}}$ rocking, and at $1246 \mathrm{~cm}^{-1}$ to $\mathrm{CH}_{3}$ symmetric bending and finally $1461 \mathrm{~cm}^{-1}$ to $\mathrm{CH}_{2}$ asymmetric bending. These infrared bands' characteristics confirm the existence of linear alkane chain substituents in the synthesized surfactants. However, the bands located at 1615 and $922 \mathrm{~cm}^{-1}$ attributed to the stretching modes of $\mathrm{C}=\mathrm{C}$ and $\mathrm{C}-\mathrm{H}$ confirm the presence of alkene chain substituents in the molecular structure of prepared surfactants. The large band located at $3436 \mathrm{~cm}^{-1}$ was attributed to the stretching of $\mathrm{O}-\mathrm{H}$ bending. All the prepared surfactants share the same functional groups and in turn the same chemical bonds.

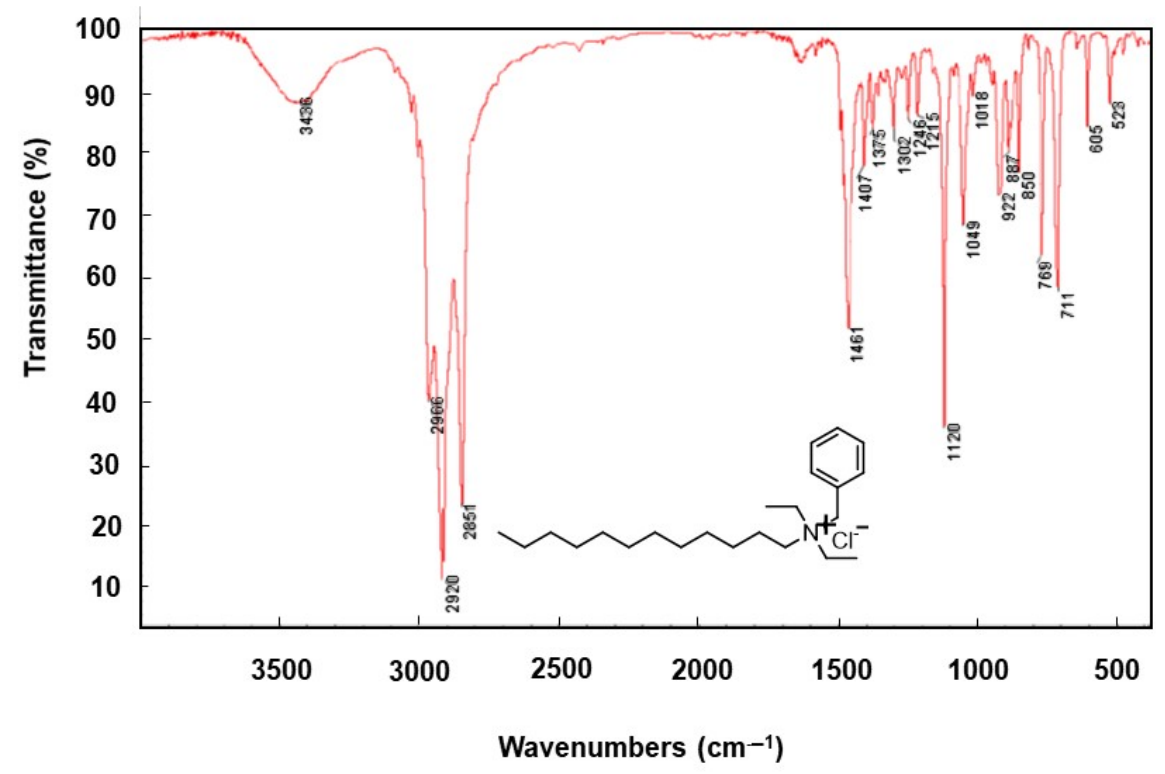

Figure 1. Infrared spectra of indicated surfactant 3. 
The steel electrodes were polished by sanding paper of various grain sizes as described in the experimental section, and the average surface roughness (RMS) was measured by using the profilometer. The measured $\mathrm{Rq}$ is about $2.41 \mathrm{~nm}$ for polished steel electrodes. Additionally, their morphology was characterized by FEGSEM, and the obtained patterns are depicted in Figure 2. Aligned strips in a given direction dominate the surface morphology.
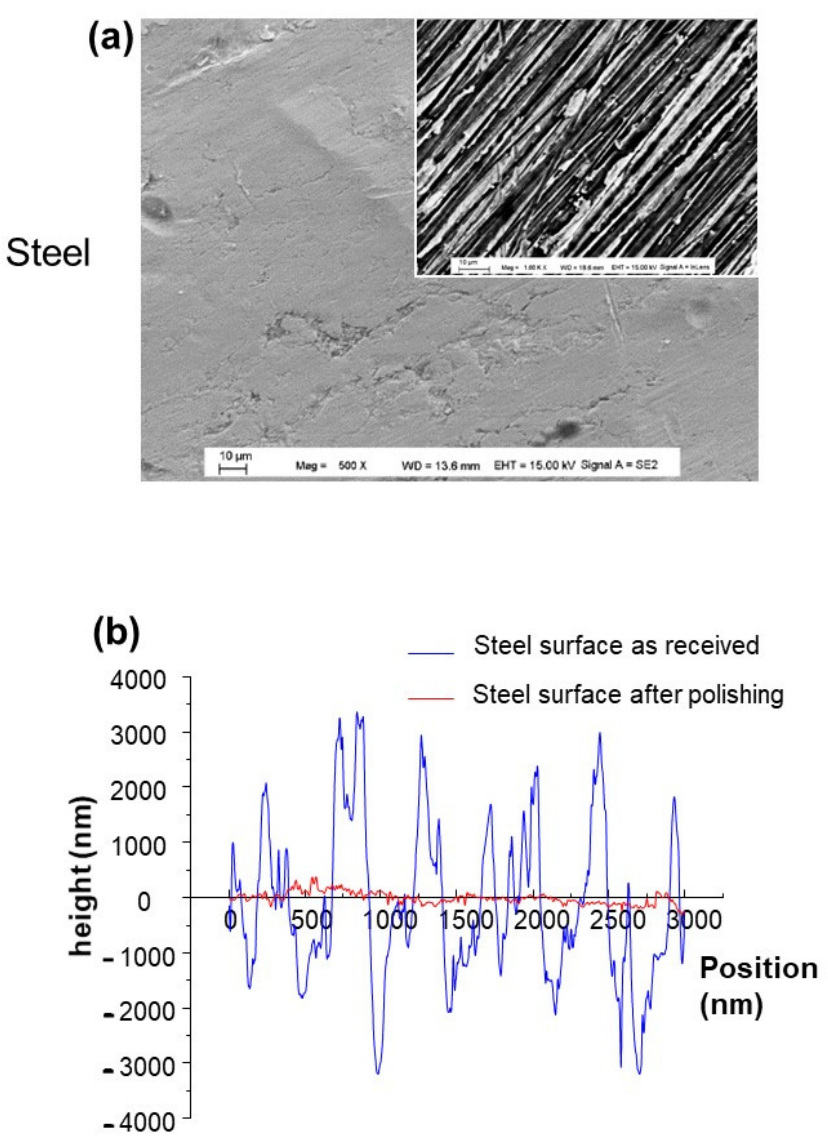

Figure 2. (a) FEGSEM images of the as-received steel and the insert corresponding to steel after polishing process; (b) the corresponding roughness.

After the polishing step, the steel electrodes were modified with synthesized surfactants, using the electrografting method described in the experimental section. The electrografting of prepared compounds was achieved by the voltammetry cyclic method using different numbers of voltammetry cycles, 12 and 24 (Figure 3). To evaluate the success of the grafting process, the surface morphology of bare and coated steel was investigated by scanning electron microscopy (FEGSEM) and X-ray photoelectron spectroscopy (XPS).

XPS characterization of bare and grafted electrodes was achieved, and the corresponding survey spectra were compared (Figure 4a). From C1s core level spectra of bare and grafted steel electrode (Figure $4 \mathrm{~b}$ ), it can be observed that on the bare steel electrode, a weak signal was detected, whereas on the grafted steel electrode, there is the appearance of intense peaks corresponding to C1s core level and assigned to carbon of aliphatic and cyclic substituents (Figure $4 \mathrm{~b}$ ). These results indicate the existence of large number of carbon atoms on the surface of the steel electrodes, which confirms the success of the grafting process. 


\section{(a)}

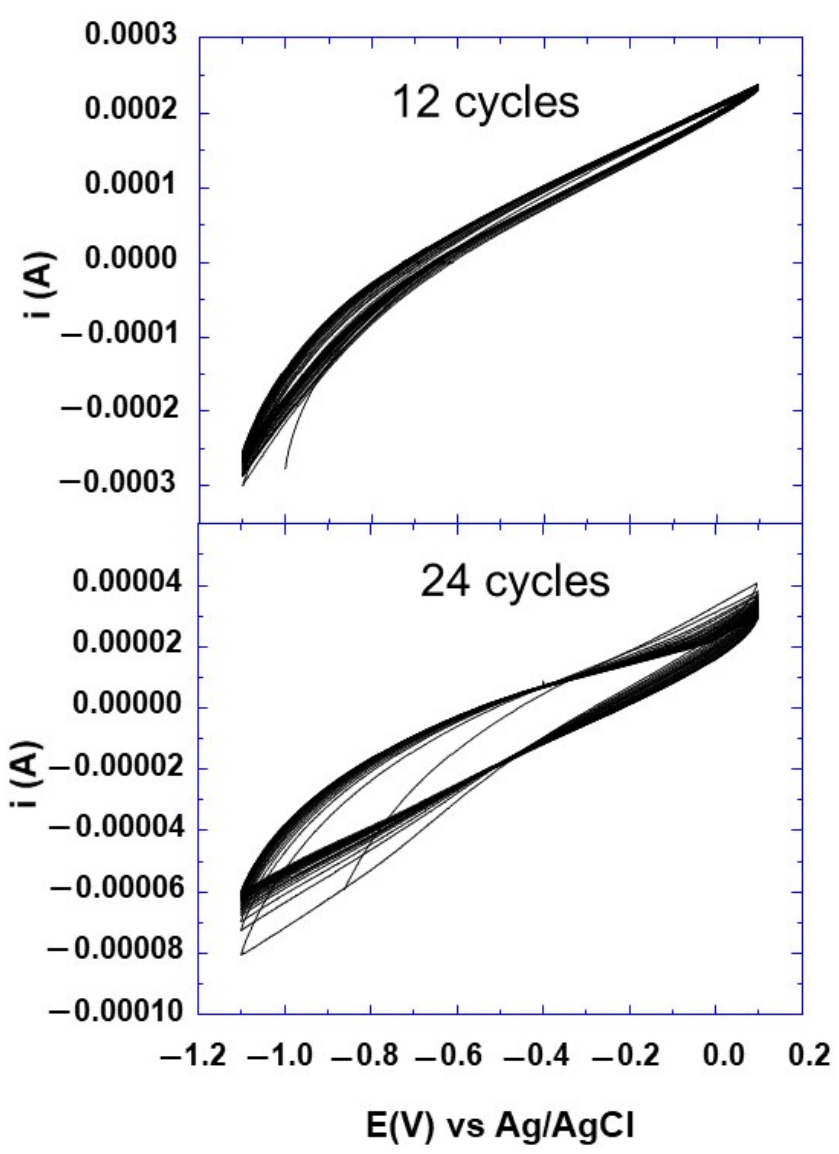

Figure 3. Cyclic voltammogram at scan rate of $10 \mathrm{mV} / \mathrm{s}$ of surfactant 5 during 12 (a) and 24 (b) voltammetry cycles as indicated.

Additionally, the appearance of $\mathrm{N} 1 \mathrm{~s}$ core levels after the grafting process confirms its success (Figure 4c). The surfactants were used to modify the steel electrodes surface, content $\mathrm{N}$ atoms and not the steel electrode. In fact, $\mathrm{N}$ 1s core level spectra are characterized by one peak located at $408.75 \mathrm{eV}$, which corresponds to chemical environments of $\mathrm{N}$ atoms, present in modified steel electrodes and absent for bare steel electrodes without surfactant modification (Figure 4c). The peak at $401.25 \mathrm{eV}$ present before and after grafting is associated with surface contamination. The other surfactants were checked using the XPS characterization and the same procedure was followed to confirm the success of the electrode grafting.

Further confirmation of the surfactants' electrografting success was provided by the FEGSEM characterization. It can be observed from Figure 5 that the surface strip's structure observed after the polishing process disappears after the grafting process, when the black domains appear on the surface. This confirms the adsorption of surfactants layer on the steel electrodes surface, which completely hid the underlying strips' structure (insert Figure $5 a, b)$. Furthermore, the effectiveness of the prepared inhibitor thin film depends on the length and structure of the carbon chain of the organic molecule grafted onto the electrode surface, as well as the electrografting conditions [28].

In order to provide additional confirmation of surfactants electrografting success, the wetting properties of the grafted steel with synthesized surfactants were investigated, and the corresponding water contact angle measurements were conducted. The obtained results are reported on Figure 6, and it can be observed that there are variations of the contact angle after the steel surface grafting. After polishing, the bare steel electrode exhibits hydrophilic behavior with a contact angle near $63.7^{\circ}$. After the grafting process, the water contact angles of the modified steel electrodes increase to between $70^{\circ}$ and $90^{\circ}$, 
with hydrophobic behavior for surfactant 3 . The change in contact angle is well known to confirm the efficiency of the grafting process and the formation of surfactant thin films.

Indeed, the change in contact angle is very sensitive to the molecular structure on the substrate surface and provides crucial information regarding the compactness of the molecules. A high contact angle corresponds to an ordered molecular structure at the substrate surface, and to weaker polar interactions between the surfactant layer and the aqueous solution.

(a)

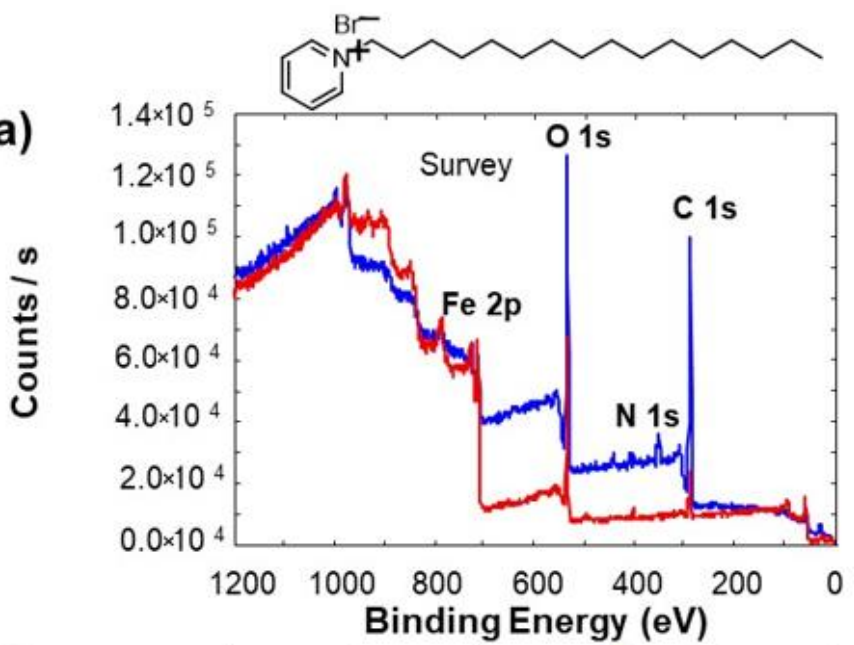

(b)
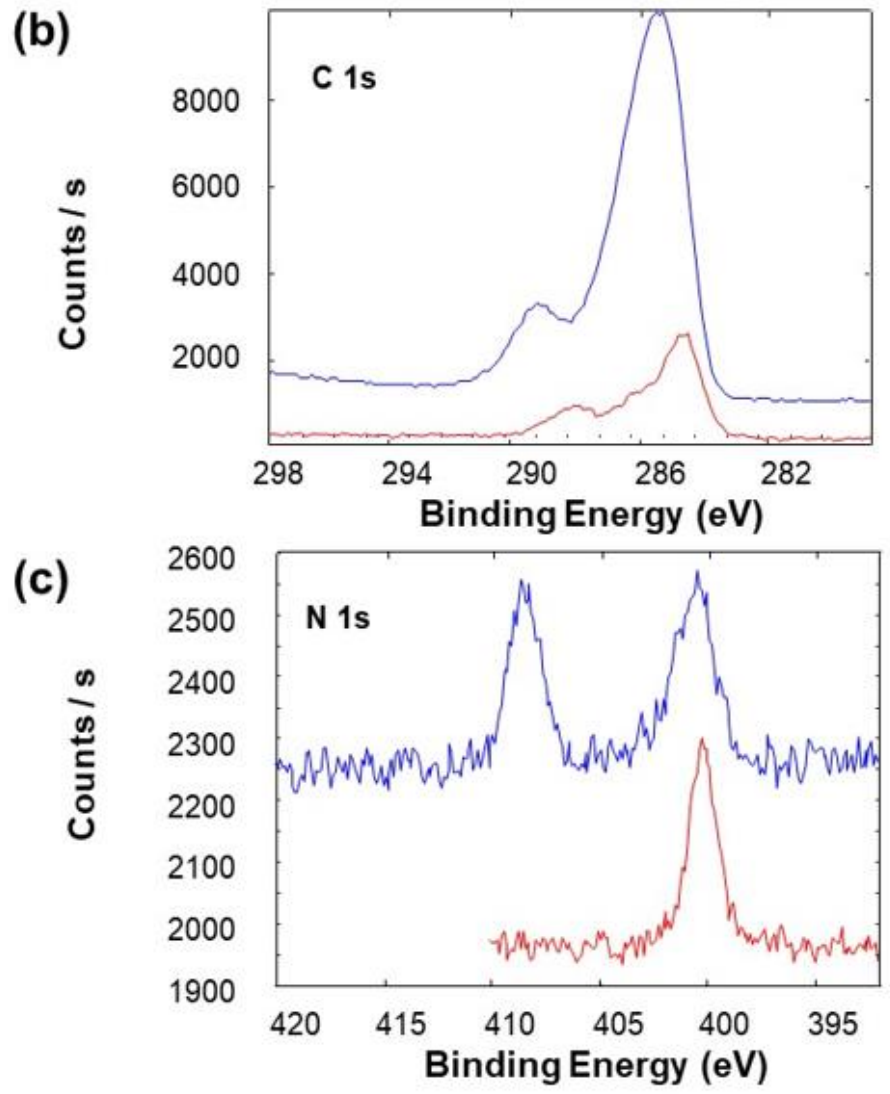

Figure 4. XPS spectra of the electrografted steel with surfactant 4 (blue color) and of bare steel (red color): (a) the survey, (b) the C1s core level and (c) the N1s core level. 


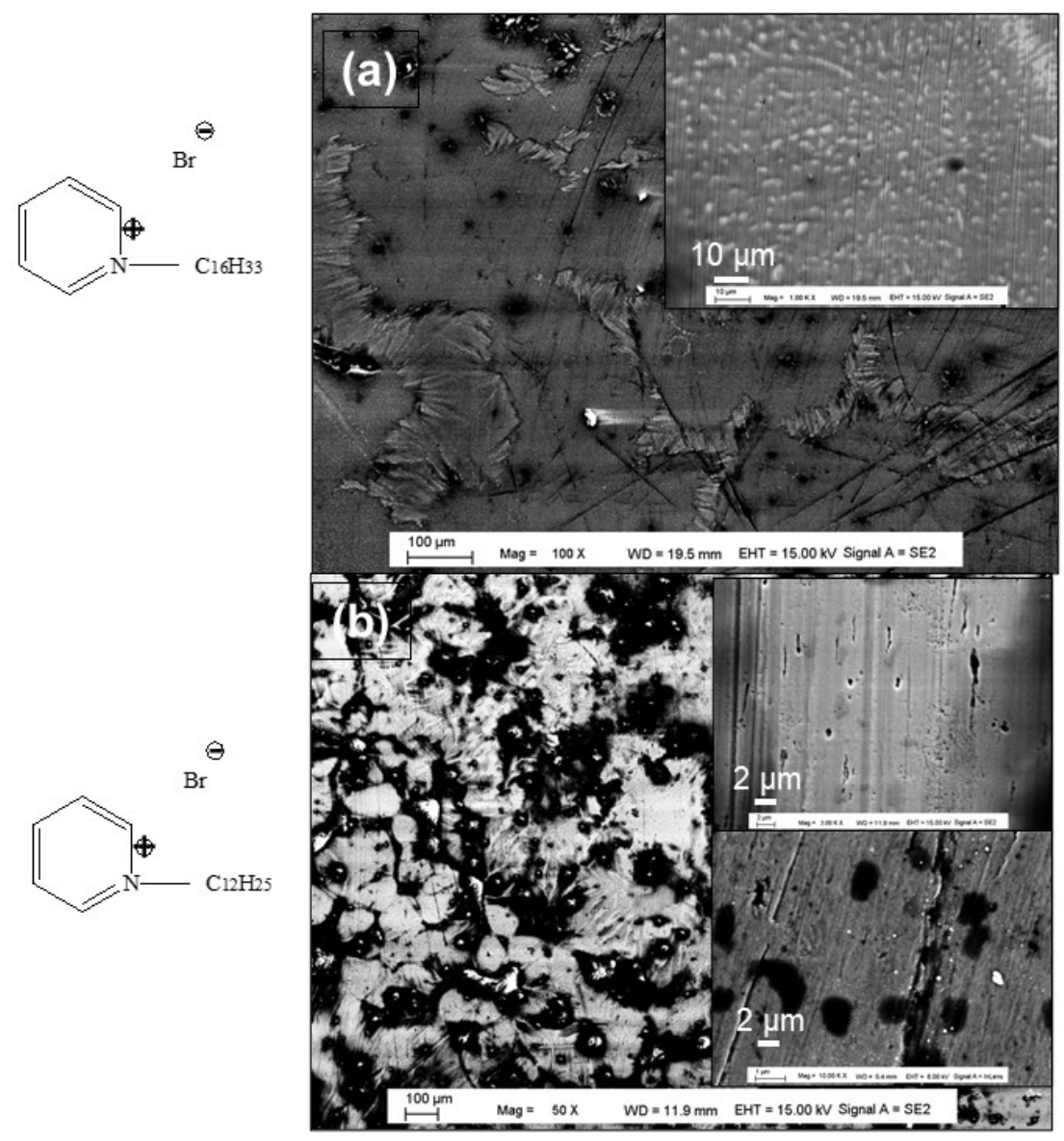

Figure 5. FEGSEM images of electrografted steel with indicated surfactants (a) surfactant 4 (b) surfactant 5 , the inserts are the corresponding high magnifications of different surface zones.

The Tafel polarization curves of tested modified steel electrodes are depicted in Figures 7 and 8 . The corrosion current (Icorr) and corrosion potential (Ecorr), as well as the cathodic (bc) and anodic (ba) slopes, are determined by extrapolating the linear region of the plots. The extracted parameters from Tafel polarization curves are presented in Table 2. Usually, higher corrosion potential Ecorr and lower corrosion current Icorr values characterize the corrosion resistance effectiveness of the surfactant layer. Furthermore, the values of cathodic (bc) and anodic (ba) slopes obtained from the Tafel curves show a slight shift compared to those of bare steel, which confirms that the surfactants have an inhibition action on the corrosion reaction (Table 2).

From Figure 7, it can be observed that both cathodic and anodic Tafel curves corresponding to bare steel and modified steel with surfactants 1, 2, 4 and 5 are parallel, which suggest that these surfactants in the indicated aggressive solution do not change the mechanism of metal dissolution and the hydrogen evolution reaction [13]. In addition, it is observed that the grafted steel, during different numbers of voltammetry cycles, shows low corrosion current variation compared to that of the bare steel electrode. Furthermore, it can be observed from Figure 7 that the Ecorr values are slightly shifted toward both cathodic and anodic potentials, without any definite trend. This reveals that these cationic surfactants provide very weak anodic and cathodic inhibitions of the corrosion reaction. Additionally, very weak improvement was observed with the number of tested electrografting cycles (12 and 24). 

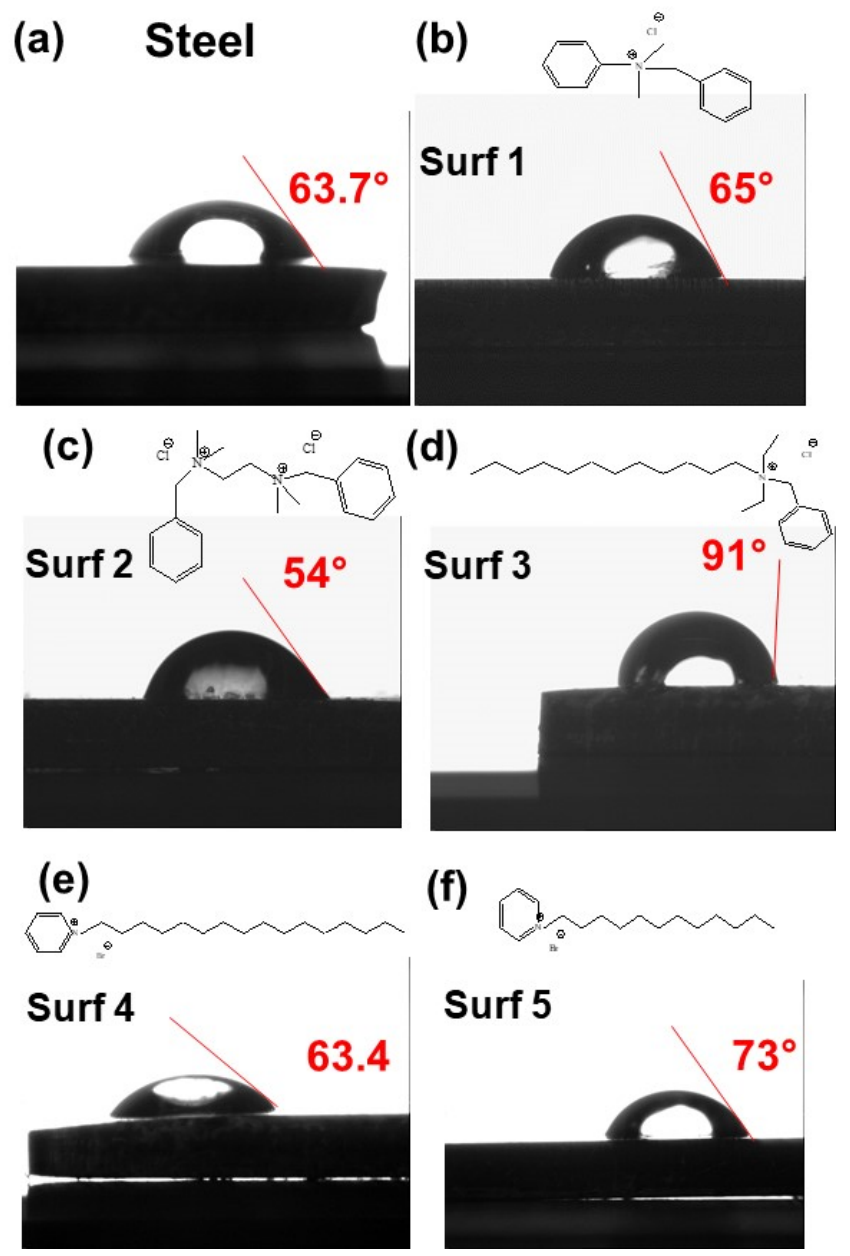

Figure 6. Contact angle of electrografted steel with indicated surfactants (a) bare steel, (b) surfactant 1 , (c) surfactant 2, (d) surfactant 3, (e) surfactant 4 and (f) surfactant 5.

Table 2. Extracted parameters from Tafel polarization curves for different prepared surfactants and indicated conditions of concentration, media and number of cycles.

\begin{tabular}{|c|c|c|c|c|c|}
\hline & \multicolumn{5}{|c|}{$\mathrm{NaCl}$} \\
\hline & I Corr $\mu \mathrm{A}$ & E Corr $(\mathrm{mV})$ & Corr Rate mm/year & ba $\left(\mathrm{mV} \mathrm{dec}{ }^{-1}\right)$ & bc $\left(\mathrm{mV} \mathrm{dec}{ }^{-1}\right)$ \\
\hline Surf $1,0.005 \mathrm{M}$ & 18 & -481.4 & $21.36 \times 10^{-2}$ & 73.5 & 79.4 \\
\hline Surf $1,0.0002 \mathrm{M}$ & 1.139 & -677.3 & $1.32 \times 10^{-2}$ & 18.5 & 42.8 \\
\hline Surf $2,0.005 \mathrm{M}$ & 0.761 & -673.4 & $0.88 \times 10^{-2}$ & 15.8 & 24.1 \\
\hline Surf 2, $0.00002 \mathrm{M}$ & 0.521 & -812.7 & $0.61 \times 10^{-2}$ & 24.5 & 42.7 \\
\hline Surf $4,0.005 \mathrm{M}$ & 0.833 & -745.9 & $0.97 \times 10^{-2}$ & 21.6 & 54.9 \\
\hline Surf $4,0.0002 \mathrm{M}$ & 0.253 & -823.3 & $0.29 \times 10^{-2}$ & 13.4 & 14.5 \\
\hline Surf 5, $0.005 \mathrm{M}$ & 0.056 & -940.9 & $0.02 \times 10^{-2}$ & 5.5 & 6.7 \\
\hline Surf 5, $0.0002 \mathrm{M}$ & 1.391 & -636.5 & $1.62 \times 10^{-2}$ & 12.7 & 31.3 \\
\hline Surf 3, $0.005 \mathrm{M}, 12$ Cyc & 1.168 & -960.0 & $1.36 \times 10^{-2}$ & 33.2 & 39.2 \\
\hline Surf 3, 0.005 M, 24, Cyc & 0.012 & -535.9 & $0.02 \times 10^{-2}$ & 18.7 & 20.9 \\
\hline Surf 3, $0.0002 \mathrm{M}, 12$ Cyc & 0.849 & -679.3 & $0.99 \times 10^{-2}$ & 18.6 & 18.7 \\
\hline Surf 3, $0.0002 \mathrm{M}, 24$, Cyc & 6.153 & -613.7 & $7.15 \times 10^{-2}$ & 34.2 & 54.5 \\
\hline Bare steel & 0.417 & -930.5 & $0.49 \times 10^{-2}$ & 14.5 & 19.5 \\
\hline
\end{tabular}


Table 2. Cont.

\begin{tabular}{|c|c|c|c|c|c|}
\hline & \multicolumn{5}{|c|}{$\mathrm{H}_{2} \mathrm{SO}_{4}$} \\
\hline & I corr $\mu \mathrm{A}$ & E corr $(\mathrm{mV})$ & Corr rate mm/year & ba $\left(m V \operatorname{dec}^{-1}\right)$ & $\mathrm{bc}\left(\mathrm{mV} \mathrm{dec}^{-1}\right)$ \\
\hline Surf $1,0.005 \mathrm{M}$ & 25.664 & -15.81 & $0.0029 \times 10^{-2}$ & 12.02 & 13.8 \\
\hline Surf $1,0.0002 \mathrm{M}$ & 33.976 & -839.7 & $39.476 \times 10^{-2}$ & 21.3 & 45.7 \\
\hline Surf 2, $0.005 \mathrm{M}$ & 23.838 & -441.3 & $27.7 \times 10^{-2}$ & 19.0 & 21.0 \\
\hline Surf $2,0.00002 \mathrm{M}$ & 7.952 & -711.8 & $9.24 \times 10^{-2}$ & 18.3 & 40.6 \\
\hline Surf $4,0.005 \mathrm{M}$ & 8.625 & -794.6 & $10.023 \times 10^{-2}$ & 19.0 & 24.4 \\
\hline Surf $4,0.0002 \mathrm{M}$ & 9.153 & -424.1 & $10.636 \times 10^{-2}$ & 15.7 & 19.1 \\
\hline Surf 5, $0.005 \mathrm{M}$ & 1.551 & -1055.1 & $1.8024 \times 10^{-2}$ & 9.1 & 12.9 \\
\hline Surf 5, $0.0002 \mathrm{M}$ & 16.05 & -451.0 & $18.65 \times 10^{-2}$ & 17.6 & 18.6 \\
\hline Surf 3, $0.005 \mathrm{M}, 12$ Сус & 4.213 & -947.3 & $4.8958 \times 10^{-2}$ & 9.5 & 22.0 \\
\hline Surf 3, $0.005 \mathrm{M}, 24$, Cyc & 0.022 & -302.6 & $0.0255 \times 10^{-2}$ & 13.4 & 23.8 \\
\hline Surf 3, $0.0002 \mathrm{M}, 12$ Сус & 36.306 & -405.5 & $42.187 \times 10^{-2}$ & 12.3 & 22.2 \\
\hline Surf 3, $0.0002 \mathrm{M}, 24$, Сус & 8.2021 & -467.3 & $9.5308 \times 10^{-2}$ & 15.0 & 27.2 \\
\hline \multirow[t]{3}{*}{ Bare steel } & 5.561 & -711.3 & $6.462 \times 10^{-2}$ & 15.4 & 21.3 \\
\hline & \multicolumn{5}{|c|}{$\mathrm{HCl}$} \\
\hline & I corr $\mu \mathrm{A}$ & E corr $(\mathrm{mV})$ & Corr rate $\mathrm{mm} /$ year & ba $\left(\mathrm{mV} \mathrm{dec}{ }^{-1}\right)$ & $\mathrm{bc}\left(\mathrm{mV} \mathrm{dec}{ }^{-1}\right)$ \\
\hline Surf $1,0.005 \mathrm{M}$ & 7.17 & -445.9 & $8.34 \times 10^{-2}$ & 9.7 & 16.8 \\
\hline Surf $1,0.0002 \mathrm{M}$ & 4.814 & -728.9 & $5.59 \times 10^{-2}$ & 51.8 & 35.4 \\
\hline Surf $2,0.005 \mathrm{M}$ & 8.659 & -467.6 & $10.062 \times 10^{-2}$ & 17.9 & 25.7 \\
\hline Surf 2, $0.00002 \mathrm{M}$ & 1.500 & -821.4 & $1.7431 \times 10^{-2}$ & 23.3 & 32.0 \\
\hline Surf $4,0.005 \mathrm{M}$ & 1.042 & -785.5 & $1.211 \times 10^{-2}$ & 20.6 & 22.1 \\
\hline Surf $4,0.0002 \mathrm{M}$ & 4.114 & -473.9 & $4.7803 \times 10^{-2}$ & $14 . .2$ & 25.0 \\
\hline Surf 5, $0.005 \mathrm{M}$ & 0.176 & -945.8 & $0.2041 \times 10^{-2}$ & 15.9 & 6.7 \\
\hline Surf 5, $0.0002 \mathrm{M}$ & 4.114 & -486.9 & $4.7519 \times 10^{-2}$ & 16.7 & 22.7 \\
\hline Surf 3, $0.005 \mathrm{M}, 12$ Сус & 0.956 & -818.2 & $1.1103 \times 10^{-2}$ & 12.5 & 15.6 \\
\hline Surf 3, $0.005 \mathrm{M}, 24$, Cyc & 0.003 & -560.6 & $0.0028 \times 10^{-2}$ & 20.9 & 27.3 \\
\hline Surf 3, $0.0002 \mathrm{M}, 12$ Сус & 11.954 & -429.4 & $13.89 \times 10^{-2}$ & 22.1 & 28.3 \\
\hline Surf 3, $0.0002 \mathrm{M}, 24$, Сус & 50.25 & -455.7 & $58.425 \times 10^{-2}$ & 46.4 & 67.0 \\
\hline Bare steel & 0.954 & -907.7 & $1.1089 \times 10^{-2}$ & 17.4 & 19.9 \\
\hline
\end{tabular}

As evidenced from Figure 8, surfactant 3 shows the best anticorrosion efficiency in different aggressive media, among the grafted layer from the other surfactants. In addition, it can be noted that the anticorrosion efficiency of surfactant 3 layer is effective in $\mathrm{HCl}, \mathrm{H}_{2} \mathrm{SO}_{4}$ and $\mathrm{NaCl}$ aggressive solutions. Furthermore, it can be observed that the corrosion current decreases compared to bare steel in $\mathrm{HCl}$ solution and the corrosion potential shifts to more positive potentials, with the number of electrografting cycles and surfactant concentration. This suggests the enhancement of the anticorrosion efficiency of the surfactant 3 grafted layer, with the number of electrografting cycles, which could be explained by the increase in surfactant molecules grafted on the surface of steel substrate. 


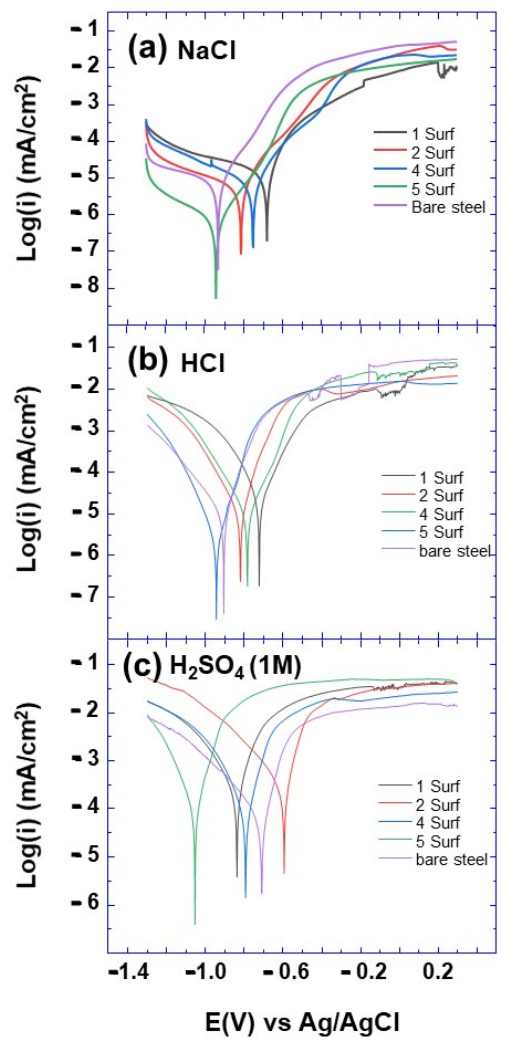

Figure 7. Polarization curves of bare and electrografted steel with different surfactants and in different media (a) $\mathrm{NaCl}$, (b) $\mathrm{HCl}$ and (c) $\mathrm{H}_{2} \mathrm{SO}_{4}$, after 12 voltammetry cycles as indicated.

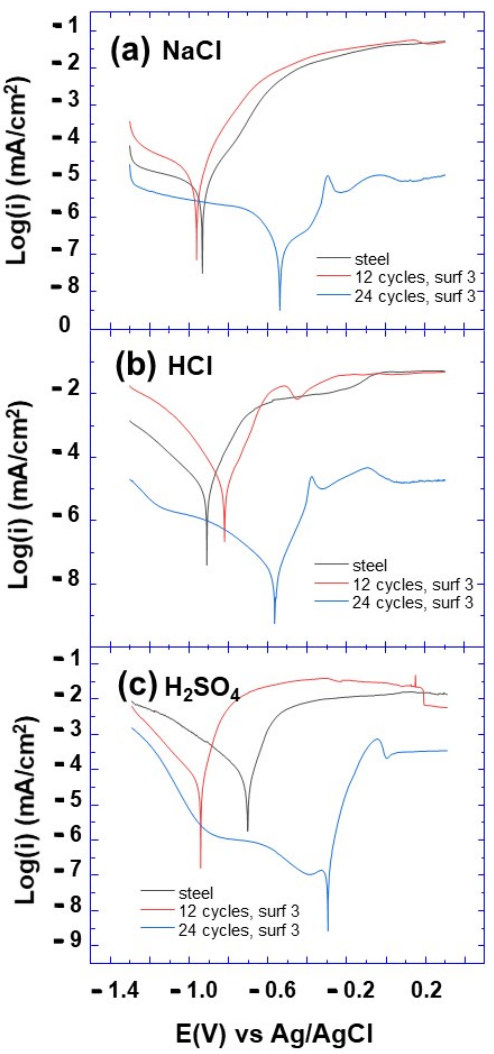

Figure 8. Polarization curves of bare and electrografted steel with surfactant 3 in different media (a) $\mathrm{NaCl}$, (b) $\mathrm{HCl}$ and (c) $\mathrm{H}_{2} \mathrm{SO}_{4}$, after 12 and 24 voltammetry cycles as indicated. 
The significant decrease in the current density was ascribed to the inhibitive barrier formed by the surfactant 3 layer on the steel surface, protecting the anodic and cathodic sites and strongly slowing the corrosive ion diffusion to the metal surface. The corrosion current (Icorr) of the surfactant 3 layer was found to decrease by 3 times, which confirms the high performance of surfactant 3 layer as an anticorrosion coating. The inhibition efficiency, $\eta$, and the rate surface coverage, $\theta$, have been reported in the literature, to be calculated using the following equations [33]

$$
\begin{gathered}
\eta=\frac{\text { icorr }- \text { iocorr }}{\text { iocorr }} \times 100 \\
\theta=\frac{\text { icorr }- \text { io }(\text { corr })}{\text { io }(\text { corr })}
\end{gathered}
$$

where io (corr) and icorr correspond to the current density with the presence and the absence of inhibitor on steel surface, respectively. Using Equation (8), the inhibition efficiencies were calculated for surfactant $3(0.005 \mathrm{M})$ in different media, and the obtained values are $97.03 \%, 99.74 \%$ and $99.61 \%$ in $\mathrm{NaCl}, \mathrm{HCl}$ and $\mathrm{H}_{2} \mathrm{SO}_{4}$ media, respectively, after 24 voltammetry cycles. In addition, the surface coverage rate was calculated using Equation (9) to be $0.97,0.997$ and 0.996 for surfactant $3(0.005 \mathrm{M})$ in $\mathrm{NaCl}, \mathrm{HCl}$ and $\mathrm{H}_{2} \mathrm{SO}_{4}$ media, respectively, after 24 voltammetry cycles. To the best of our knowledge, surfactant 3 shows record inhibition efficiency with a simpler structure compared to those surfactants reported in the literature [20-24].

To explain the higher anticorrosion efficiency of surfactant 3 compared to other synthesized surfactants, it is important to discuss their properties. In fact, their structure is an important parameter to take into account. As mentioned previously, the cationic surfactant with the ammonium group exhibits efficient anticorrosion properties, and it is also enhanced by long aliphatic and aromatic substituents. It is clear from these results that the optimization of the surfactant anticorrosion properties must go through the synthesis of the surfactant, which include both mentioned substituents. By comparing the structure of the prepared surfactant, it is clear that surfactant 3 includes both substituents (Table 1), whose synergetic effect could explain its effective anticorrosion properties. In fact, long aliphatic alkyl chain could ensure a high compact barrier layer, and both ammonium group and aromatic substituent could enable strong adsorption of the surfactant on the surface [14].

The anticorrosion efficiency of surfactant 3 could also be explained by its wetting property. It can be observed from Figure 6 that the contact angle corresponding to the surfactant 3 layer is about $91^{\circ}$ and therefore exhibits a hydrophobic behavior. The surfactant 3 layer exhibits a higher hydrophobic character and about a 3 times lower corrosion rate than the bare steel electrode. This shows that the hydrophobic character of the surfactant 3 layer plays a role in its anticorrosion efficiency, compared to other surfactants and the bare steel electrode in the tested aggressive media $\left(\mathrm{HCl}, \mathrm{H}_{2} \mathrm{SO}_{4}, \mathrm{NaCl}\right)$. The enhanced anti-corrosion efficiency with the layer hydrophobic character was observed by different authors [32,33] and was explained by the reduced wetted area on the solid surface in contact with the aggressive solution. In fact, the hydrophobic property of the surfactant 3 layer is the signature of its high close packing, which will improve the effectiveness of its barrier effect by keeping the corrosive media away from the surface of the steel electrode, thus generating better anticorrosion protection. It has been reported in the literature that the packing density and the rate of surfactant layer formation depend on the position of the aromatic group in the alkyl chain. Surfactants with a longer alkyl chain, oriented toward the corrosive environment, exhibit faster layer formation and generally higher close packing density [36]. In fact, the alkyl chain could act as a driving force to form the surfactant layer through the optimization of van der Waals forces. This could explain the performance of surfactant 3 compared to surfactants 1 and 2 .

Further understanding of our experiments is provided by the FEGSEM patterns in Figure 9. It can be observed that the grafted steel electrode is heterogeneous in terms of color and structure. The black and gray colors correspond most likely to the grafted 
surfactant layer and the slightly corroded steel surface areas, respectively, whereas cracked and nanostructured regions could be assigned to the thick oxide film formed during the corrosion process. It can be noted that the black areas are not corroded, and thus are likely more protected, whereas the gray areas are corroded at different rates. The surfactant density could explain these results on the steel surface; likely, black regions correspond to the surfactant layer with higher close packing density (high surface coverage) compared to those of the gray color. Additionally, the regions with the gray color are made of monolayer surfactants with different low densities (low surface coverage), which could explain the fact that this region has weak protection, and it is corroded with different rates.
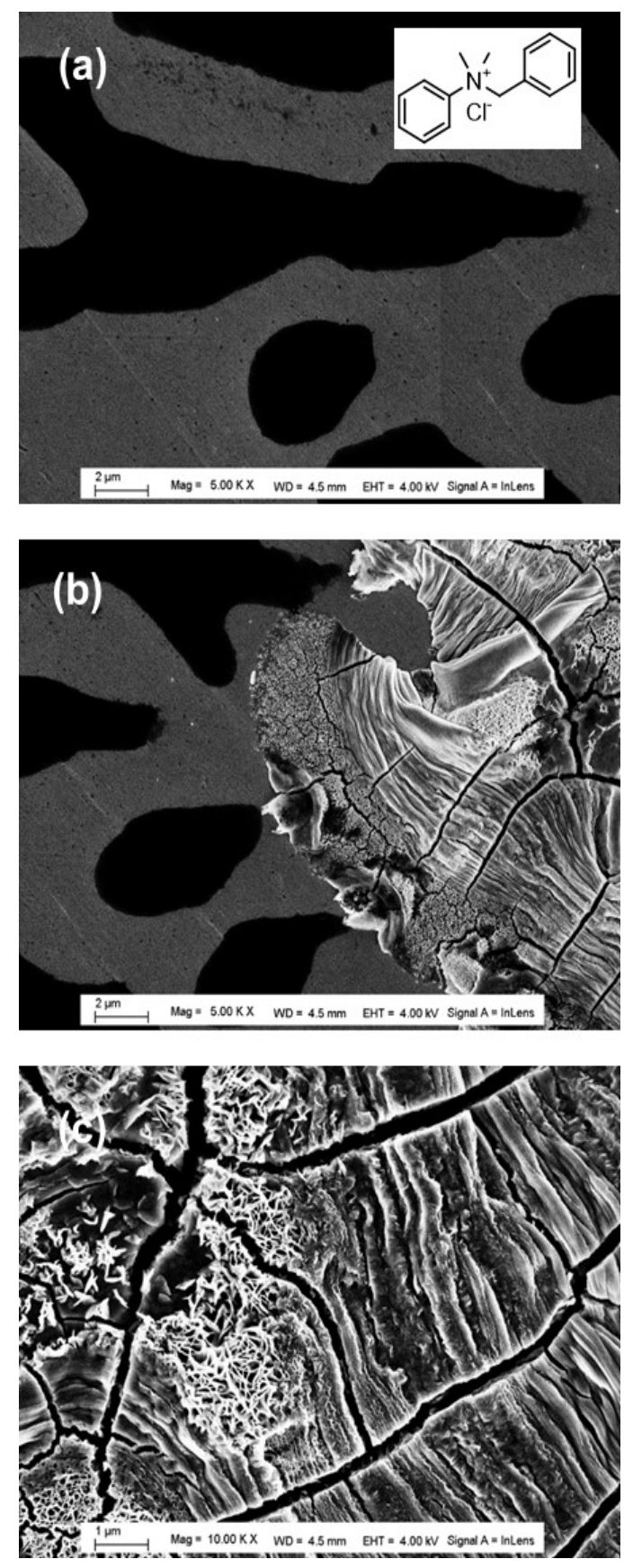

Figure 9. FEGSEM images at different zones of electrografted steel surface with surfactant 1 and after 24 voltammetry cycles $(\mathbf{a}, \mathbf{b})$. A high magnification in (b) corresponds to the corroded area in (c). 
For surfactant 3 , it can be observed that the layer covers a large surface area of steel electrode (Figure 10b) compared to other surfactants, which form a very discontinuous layer with many islands (Figure 10c).

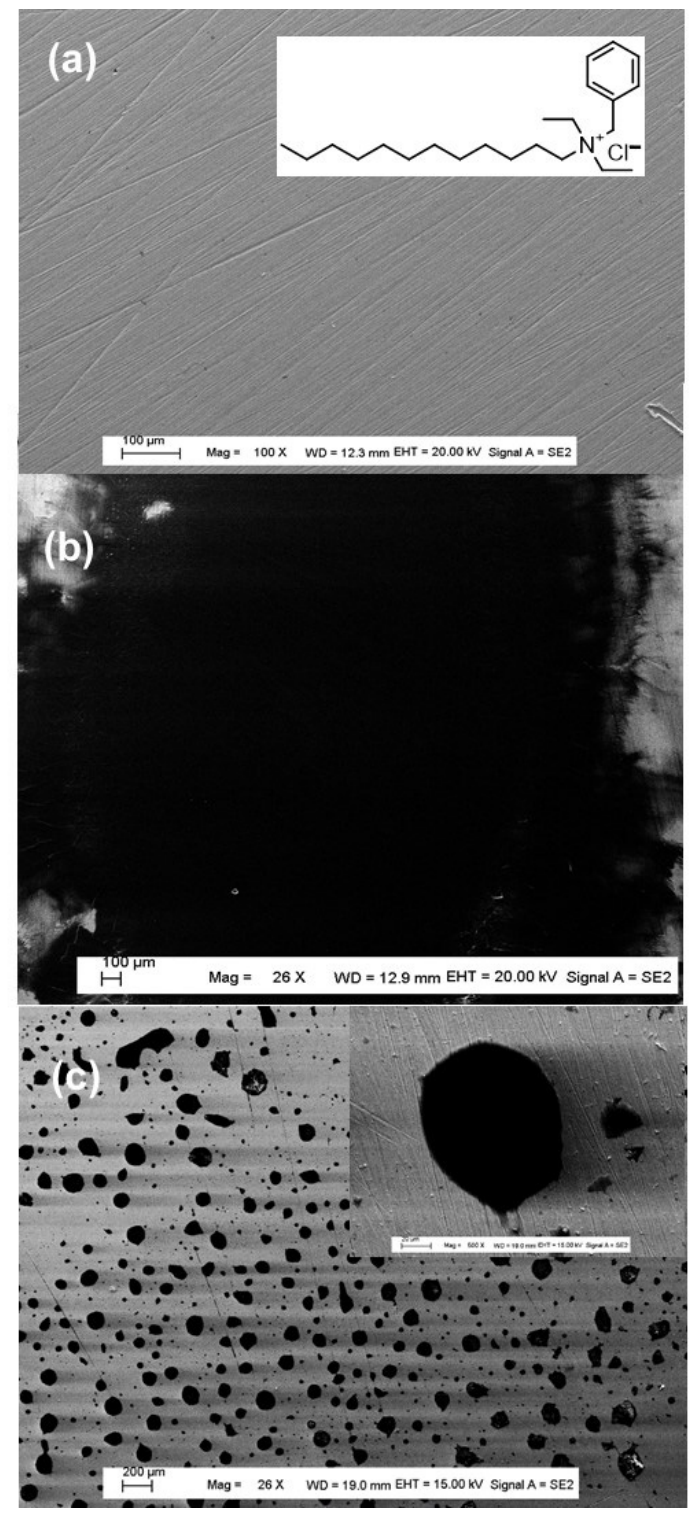

Figure 10. FEGSEM images of bare steel (a), electrografted steel with surfactant 3 (b) and with other surfactants (c). The insert of (c) is the corresponding high magnification.

The anticorrosion efficiency of ammonium surfactants could also be explained by its interaction with the substrate surface. Indeed, all surfactants interact with the substrate via their $\mathrm{N}$ atom and the delocalized $\pi$ electrons of the phenyl substituents, if any. Furthermore, the bridge between the ammonium cation and the phenyl substituent favors the interaction between the substrate and the aromatic group, which more easily undergoes different orientations to reach the equilibrium state. Additionally, this favors the strong adsorption and compactness of these surfactants on the substrate, which play a crucial role in its anticorrosion efficiency.

In fact, the electrografting of the surfactants on the substrate takes place through the electron exchange between the electron of nitrogen atom and the low-energy d-orbitals of iron surface atoms. However, the electron donor property and electron availability of different groups favors the electron exchange induced by the applied potential. In addition 
to this electronic aspect, the low steric effect of the surfactant's substituents could play an important role in the success of the electrografting process.

From the present results, the low-rate coverage of surfactant 1,2, 4 and 5 ranging from 0.4 to 0.55 , as observed from the FEGSEM experiments (Figure 10c), could be explained by their low electrografting on the surface, because of steric effect and/or electron availability for electron exchange at the applied potential. In fact, electro-delocalization could offer several possibilities for the surfactant electrografting, which could lead to the formation of a disordered layer with a low packing density. The rate of coverage of the electrode surface varies for each surfactant at the same concentration, which indicates that the surfactant's structure and assembly also play a major role.

To better understand the observed behaviors, we considered the assembly of surfactants into micelles [37], and we plotted the conductivity versus different concentrations for each surfactant. From these curves, we can deduce the critical micellar concentration of each surfactant, which is the intersection of the two linear behaviors of the conductivity versus the concentrations [37].

The critical micelle concentration (CMC) is one of the surfactant parameters to be considered for the effectiveness of surfactant-based corrosion inhibitors. Increasing the surfactant concentration below the CMC promotes surfactant aggregation at the metal interface, which reduces surface tension. Above the $\mathrm{CMC}$, the metal surface is saturated with surfactant molecules and the excess molecules aggregate in the solution to form micelles or multilayers of surfactants at the metal interface. As a result, the surface tension and corrosion rate are not disturbed [38].

By comparing the critical micelle concentration $\left(\mathrm{C}_{\mathrm{cmc}}\right)$ of each surfactant with the concentration of about $0.005 \mathrm{M}$ used for the experiments, it can be noted that for surfactant 3 , the $C_{\mathrm{cmc}}$ is higher than the used concentration, whereas for other surfactants, the $C_{\mathrm{cmc}}$ is lower than the used concentration. In the light of these comparisons, the obtained electrochemical results could be explained as follows: for surfactant 3 , as its $C_{\mathrm{cmc}}$ is higher than the used concentration (Figure 11, Table 3), the conductivity change is not clear from the curve (Figure 11), which means that it will take place at a higher concentration. In this situation, the better results of surfactant 3 , whose $\mathrm{CMC}$ is higher than its concentration (Table 3), can be explained by the fact that the electrografting process is the driving force for the saturation of the metal interface and not the surfactant concentration. If we consider that the concentration of surfactant above the CMC should cause the aggregation of surfactant at the metal interface to reach a monolayer saturation, this would result in better protection of the metal by the surfactant. This is not the case, according to our results for surfactants 1 , 2, 4 and 5 in terms of nonhomogeneous surfactant layer on the surface of the steel electrode (Figure 10), which reduces its anticorrosion efficiency. This suggests that CMC is not a determining parameter in the anti-corrosion efficiency of these electrografted surfactant layers. There is no competition between the formation of micelles from the free monomers of the surfactants and their grafting onto the electrode surface. In fact, the exceeding free monomers of the surfactants aggregate to form micelles in solution [38].

By choosing the lower concentration $(0.0002 \mathrm{M})$ of surfactant 3 , it can be seen in Table 2 that the corrosion current becomes higher, which could be explained by lower available free surfactants to be electrografted on the steel surface to form a close packing surfactant layer with a high barrier effect. This confirms that the concentration and the number of voltammetric cycles are the determining parameters of the saturation of the metal surface by the surfactant and, consequently, of the anti-corrosion efficiency of the surfactant layer formed. 


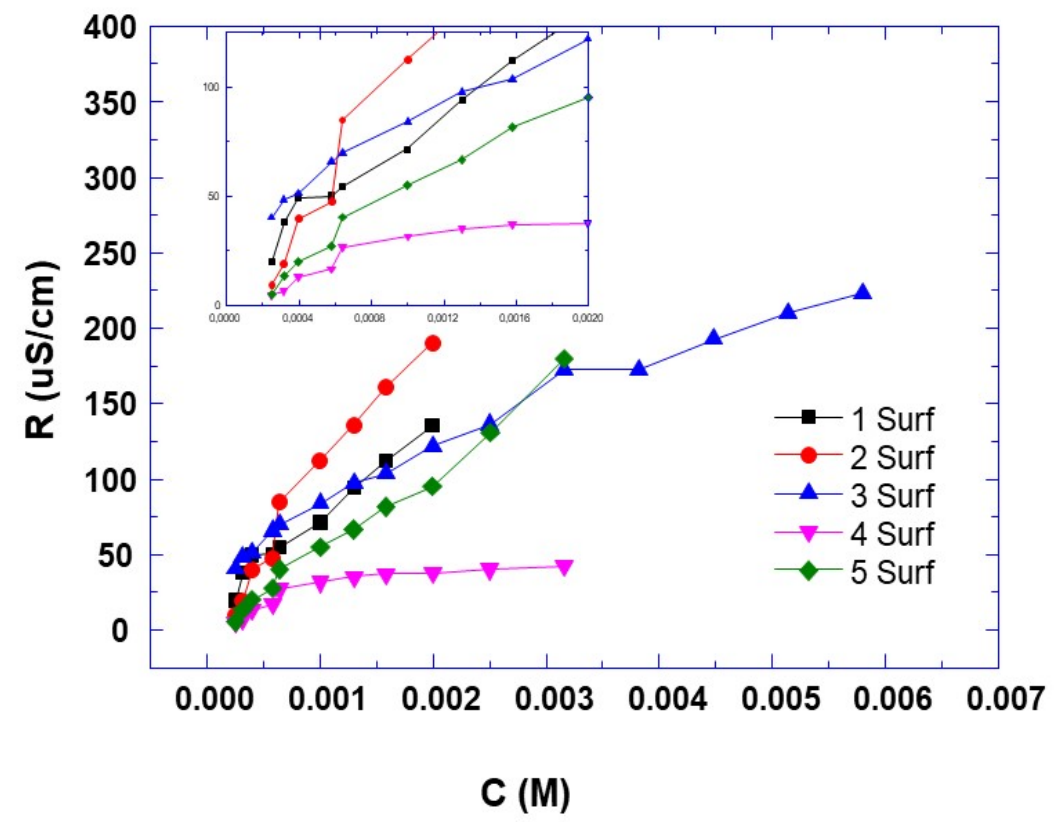

Figure 11. Plots of electrical conductivity versus concentration of prepared surfactants in water at ambient temperature.

Table 3. Critical micelle concentration (CMC) of synthesized cationic surfactants obtained from Figure 11.

\begin{tabular}{cccccc}
\hline Surfactant & $\mathbf{1}$ & $\mathbf{2}$ & $\mathbf{3}$ & $\mathbf{4}$ & $\mathbf{5}$ \\
\hline $\mathrm{C}_{\mathrm{CMC}}$ & 0.0005 & 0.00072 & - & 0.00034 & 0.0002 \\
\hline
\end{tabular}

\section{Conclusions}

In summary, different cationic surfactants based on various aliphatic and aromatic ammonium cations were synthesised and used to prepare coatings, whose anticorrosive performance was evaluated for steel protection. It was demonstrated, by different techniques, that prepared surfactants were successfully electrografted on the polished steel electrode surface. Among the synthesized molecules, only surfactant 3 enabled the hydrophilic-tohydrophobic transition of the grafted electrodes' surface and protection against corrosion for steel in different aggressive media $\left(\mathrm{HCl}, \mathrm{NaCl}\right.$ and $\left.\mathrm{H}_{2} \mathrm{SO}_{4}\right)$. The analysis of Ecorr and Icorr of the synthesized surfactants shows that surfactant 3 remarkably limits the diffusion of corrosive ions to the steel surface, which protects the metal from dissolution through the synergetic effect of barrier and hydrophobic characters provided by the electrografted surfactant coating. The corrosion rate of the surfactant layer was found to decrease up to three times in $\mathrm{NaCl}$, which proved its high anticorrosion performance with efficiency of around $99 \%$. Finally, it has been shown that the choice of surfactant concentration is independent of its $\mathrm{Ccmc}$, and the formation of a homogeneous and close packing surfactant layer with efficient anticorrosion properties depends on the surfactant concentration and the number of voltammetry cycles. The molecular structure of surfactants is a crucial parameter to consider in the design of inhibitors for improved efficiency of the anticorrosion coatings they can form. The hydrophobic and barrier properties of the coatings are the consequence of a synergistic effect of the aliphatic and aromatic substituents of the surfactants.

Author Contributions: Conceptualization, A.T.; methodology, A.T., V.B. and A.C.; validation, A.T.; investigation, H.P.; S.F., S.M., N.K. and S.Z.; resources, A.T. and V.B.; data curation, H.P., S.F., Y.X. and S.Z.; writing—original draft preparation, A.T. and H.P.; writing—review and editing, A.T., H.P., Y.X., V.B. and A.C.; visualization, Y.X.; supervision, A.T.; funding acquisition, A.T. All authors have read and agreed to the published version of the manuscript. 
Funding: This research was funded by the European Union's Horizon 2020 research and innovation program under the Marie Sklodowska-Curie grant agreement no. 734276.

Institutional Review Board Statement: Not applicable.

Informed Consent Statement: Not applicable.

Data Availability Statement: Data available on request due to restrictions privacy.

Acknowledgments: The authors would like to thank the Tunisian Ministry of Higher Education for supporting S. Falah with a Bourse d'Alternance scholarship.

Conflicts of Interest: The authors declare that they have no known competing financial interests or personal relationships that could have appeared to influence the work reported in this paper.

\section{References}

1. Crossland, I.G. Handbook of Advanced Radioactive Waste Conditioning Technologies; Woodhead Publishing: Cambridge, UK; Philadelphia, PA, USA, 2011; p. 512.

2. Buchanan, R.A.; Stansbury, E.E. Handbook of Environmental Degradation of Materials, 2nd ed.; William Andrew Publishing: Norwich, NY, USA, 2012; pp. 87-125.

3. Kharitonov, D.S.; Dobryden, L.; Sefer, B.; Ryl, J.; Wrzesińska, A.; Makarova, I.V.; Bobowska, I.; Kurilo, I.I.; Claesson, P.M. Surface and corrosion properties of AA6063-T5 aluminum alloy in molybdate-containing sodium chloride solutions. Corr. Sci. 2020, 171, 108658. [CrossRef]

4. Mohsin, N.M.B.; Khaleel, H.H.; Dhaher, N.H.; Aljamali, N.M. Preparation of chemical inhibitors to treat the corrosion and erosion of machines. IJEAM 2019, 54, 89.

5. Asefi, D.; Arami, M.; Mahmoodi, N.M. Electrochemical effect of cationic gemini surfactant and halide salts on corrosion inhibition of low carbon steel in acid medium. Corr. Sci. 2010, 25, 794-800. [CrossRef]

6. Nilsson, A.; Pettersson, L.G.M. Chemical Bonding on Metal Surfaces. In Model Systems in Catalysis; Rioux, R., Ed.; Springer: Berlin/Heidelberg, Germany, 2010; pp. 253-274.

7. Qiu, L.G.; Wang, Y.M.; Jiang, X. Synergistic effect between cationic gemini surfactant and chloride ion for the corrosion inhibition of steel in sulfuric acid. Corr. Sci. 2008, 50, 576-582. [CrossRef]

8. Soror, T.Y.; El-Ziady, M.A. Effect of cetyltrimethyl ammonium bromide on the corrosion of carbon steel in acids. Mater. Chem. Phys. 2002, 77, 697-703. [CrossRef]

9. Bahrami, M.J.; Hosseini, S.M.A.; Pilvar, P. Experimental and theoretical investigation of organic compounds as inhibitors for mild steel corrosion in sulfuric acid medium. Corr. Sci. 2010, 52, 2793-2803. [CrossRef]

10. Gece, G.; Bilgic, S. Quantum chemical study of some cyclic nitrogen compounds as corrosion inhibitors of steel in NaCl media. Corr. Sci. 2009, 51, 1876-1878. [CrossRef]

11. Katriya, M.N.; Jana, A.K.; Parikh, P.A. Corrosion inhibition effectiveness of zeolite ZSM-5 coating on mild steel against various organic acids and its antimicrobial activity. J. Ind. Eng. Chem. 2013, 19, 286. [CrossRef]

12. Raja, P.B.; Qureshi, A.K.; Rahim, A.A.; Osman, H.; Awang, K. Neolamarckia cadamba alkaloids as eco-friendly corrosion inhibitors for mild steel in $1 \mathrm{M} \mathrm{HCl}$ media. Corr. Sci. 2013, 69, 292. [CrossRef]

13. Shaban, S.M.; Saied, A.; Tawfik, S.M.; Abd-Elaal, A.; Aiad, I. Inhibition of mild steel corrosion in acidic medium by some cationic surfactants. J. Ind. Eng. Chem. 2013, 19, 2004-2009. [CrossRef]

14. Noor, E.A. The inhibition of mild steel corrosion in phosphoric acid solution by some N-heterocyclic compounds in the salt form. Corr. Sci. 2005, 47, 33-55. [CrossRef]

15. Wang, X.P.; Xiao, H.B. Synthesis of Amide-Based Surfactant Inhibitor for Carbon Steel Corrosion Protection Electrochemical Analysis. Int. J. Electrochem. Sci. 2017, 12, 268-279. [CrossRef]

16. Hamza, M.M.; Abd El Rehim, S.S.; Magdy, A.M. Ibrahim Inhibition effect of hexadecyl pyridinium bromide on the corrosion behavior of some austenitic stainless steels in $\mathrm{H}_{2} \mathrm{SO}_{4}$ solutions. Arab. J. Chem. 2013, 6, 413-422. [CrossRef]

17. Frignani, A.; Tassinari, M.; Mezaros, L.; Trabanelli, G. The use of electrochemical impedance spectroscopy to study ARMCO iron corrosion in acid solution inhibited by quaternary ammonium compounds. Corr. Sci. 1991, 32, 903-911. [CrossRef]

18. Subramaniam, G.; Balasubramaniam, K.; Sridhar, P. Bis pyridinium compounds as corrosion inhibitors. Bull. Electrochem. 1990, 6, 225.

19. Martinez, S.; Metikoš-Huković, M. A nonlinear kinetic model introduced for the corrosion inhibitive properties of some organic inhibitors. J. Appl. Electrochem. 2003, 33, 1137-1142. [CrossRef]

20. Hegazy, M.A.; Abdallah, M.; Award, M.K.; Rezk, M. Three novel di-quaternary ammonium salts as corrosion inhibitors for API X65 steel pipeline in acidic solution. Part I: Experimental results. Corros. Sci. 2014, 81, 54-64.

21. Hassan, H.H.; Abdelghani, E.; Amin, M.A. Inhibition of mild steel corrosion in hydrochloric acid solution by triazole derivatives: Part I. Polarization and EIS studies. Electrochim. Acta. 2007, 52, 6359-6366. [CrossRef]

22. Khaled, K.F.; Abdel-Rehim, S.S.; Sakr, G.B. On the corrosion inhibition of iron in hydrochloric acid solutions, Part I: Electrochemical DC and AC studies. Arab. J. Chem. 2012, 5, 213-218. [CrossRef] 
23. Khaled, K.F. The inhibition of benzimidazole derivatives on corrosion of iron in $1 \mathrm{M} \mathrm{HCl} \mathrm{solutions.} \mathrm{Electrochim.} \mathrm{Acta} \mathrm{2003,} 48$, 2493-2503. [CrossRef]

24. Amin, M.A.; Khaled, K.F.; Mohsen, Q.; Arida, H.A. A study of the inhibition of iron corrosion in $\mathrm{HCl}$ solutions by some amino acids. Corros. Sci. 2010, 52, 1684-1695. [CrossRef]

25. Putilova, I.N.; Balezine, S.A.; Barannik, V.P. Metallic Corrosion Inhibitors; Pergamon Press: London, UK, 1960.

26. Ayssar, N.; Ideisan, I.A.-A.; Ibrahim, A.-R. Inhibition of Mild Steel Corrosion by 3-Benzoylmethyl Benzimidazolium Hexafluoroantimonate in Acidic Solution. Int. J. Corr. 2012, 2012, 1-10.

27. Alnegren, P.; Sattari, M.; Svensson, J.-E.; Froitzheim, J. Severe dual atmosphere effect at $600{ }^{\circ} \mathrm{C}$ for stainless steel 441. J. Power Sources 2016, 301, 170-178. [CrossRef]

28. Bakhshandeh, E.; Jannesari, A.; Ranjbar, Z.; Sobhani, S.; Saeb, M.R. Anti-corrosion hybrid coatings based on epoxy-silica nano-composites: Toward relationship between the morphology and EIS data. Prog. Org. Coat. 2014, 77, 1169-1183. [CrossRef]

29. Harrtt, W.H.; Chen, S. Path dependence of the potential-current density state for cathodically polarized steel in Seawater. Corrosion 2000, 56, 3-11. [CrossRef]

30. Yates, N.D.; Dowsett, M.R.; Bentley, P.; Dickenson-Fogg, J.A.; Pratt, A.; Blanford, C.F.; Fascione, M.A.; Parkin, A. Aldehydemediated protein-to-surface tethering via controlled diazonium electrode functionalization using protected hydroxylamines. Langmuir 2020, 36, 5654-5664. [CrossRef] [PubMed]

31. Huang, W.F.; Xiao, Y.L.; Huang, Z.J.; Tsui, G.C.P.; Yeung, K.W.; Tang, C.Y.; Liu, Q. Super-hydrophobic polyaniline-TiO 2 hierarchical nanocomposite as anticorrosion coating. Mater. Lett. 2020, 258, 126822. [CrossRef]

32. Yang, S.-Y.; Hirasaki, G.J.; Basu, S.; Vaidya, R. Mechanisms for contact angle hysteresis and advancing contact angles. J. Petrol. Sci. Eng. 1999, 24, 63-73. [CrossRef]

33. Xue, Y.; Wang, S.; Zhao, G.; Taleb, A.; Jin, Y. Fabrication of Ni-Co coating by electrochemical deposition with super-hydrophobic properties for corrosion protection. Surf. Coat. Tech. 2019, 363, 352-361. [CrossRef]

34. Ding, Y.; Bruce, B.; Young, B.; Singer, M. The effect of temperature and critical micelle concentration (cmc) on the inhibition performance of a quaternary ammonium-type corrosion inhibitor. In NACE 2020; OnePetro: Texas, TN, USA, 2020 ; p. 14793.

35. Badawi, A.M.; Hegazy, M.A.; El-Sawy, A.A.; Ahmed, H.M.; Kamel, W.M. Novel quaternary ammonium hydroxide cationic surfactants as corrosion inhibitors for carbon steel and as biocides for sulfate reducing bacteria (SRB). Mater. Chem. Phys. 2010, 124, 458-465. [CrossRef]

36. Evans, S.D.; Urankar, E.; Ulman, A.; Ferris, N. Self-Assembled Monolayers of Alkanethiols containing a polar aromatic group: Effect of dipole position on molecular packing, orientation and surface wetting properties. J. Am. Chem. Soc. 1991, 113, 4121-4131. [CrossRef]

37. Hegazy, M.A.; Badawi, A.M.; Abd El Rehim, S.S.; Kamel, W.M. Corrosion inhibition of carbon steel using novel N-(2-(2mercaptoacetoxy)ethyl)-N, N-dimethyl dodecan-1-aminium bromide during acid pickling. Corr. Sci. 2013, 69, 110-122. [CrossRef]

38. Maqsood, A.M.; Mohd, A.H.; Firdosa, N.; Shaeel, A.; Al-a, Z.K. Anti-corrosion ability of surfactants: A review. Int. J. Electrochem. Sci. 2011, 6, 1927-1948. 